\title{
El fracaso del éxito: Italia en la guerra de España
}

\author{
ISMAEL SAZ
}

Me parece conveniente iniciar esta exposición señalando algunas circunstancias que a la luz de los acontecimientos posteriores nos pueden parecer extrañas. Sabemos, por ejemplo, que entendida la guerra civil como un conflicto entre fascismo y comunismo, dos potencias eran las "llamadas» a tener un protagonismo especial en la guerra de España: Italia y la URSS; sabemos también que, al final, fue así en efecto, aunque el comunismo como objetivo de actuación política no constituyese, precisamente, la guia de la actitud soviética. Sin embargo, y estas son las circunstancias extrañas que quiero subrayar, esas dos potencias llamadas a ocupar el mayor protagonismo fueron en cierto modo las últimas en acudir a la cita. En efecto, como sabemos, la URSS apenas si mostró inicialmente una simpatía "platónica» hacia la causa republicana, que en los primeros días de agosto se tradujo en campañas propagandísticas y colectas de dinero y que no llegó a tener características de ayuda militar hasta octubre ${ }^{1}$. En el caso de Italia, en seguida volveremos sobre ello, la prudencia es máxima en los primeros días del conflicto, para dar paso

' CatTELL, D.T., Soviet Diplomacy and the Spanish Civil War. Berkeley, University of California Press, 1957; del mismo, Communism and the Spanish Civil War, Berkeley, University of California Press; CARR, E.H., La Comintern y la guerra civil española. Madrid, Alianza, 1986; Haslam, J., The Soviet Union and the Struggle for Collective Security in Europe, 19331939. Londres, Macmillan, 1984, especialmente, págs. 107 ss. Vale la pena recordar aquí que los italianos eran conscientes, como, por lo demás, el resto de las grandes potencias, de la inicial retracción soviética respecto de los acontecimientos en España. Incluso después de iniciada la campaña propagandística en la URSS contra la intervención de las potencias facistas en España, la embajada italiana en Moscú seguia enfatizando el temor de las autoridades soviéticas a que un avance de los comunistas en España pudiera conducir a una ruptura del Frente Popular. Cfr. SAZ, I., Mussolini contra la II República. Valencia, IVEI, 1986, págs. 205-207. 
a un proceso de maduración-reflexión que conduciría en fecha tan tardía como el 28 de julio a la decisión en firme de apoyar a los rebeldes ${ }^{2}$.

Así pues, sabiendo que la URSS «mueve» después que Italia y que ésta no lo hace en forma significativa hasta el 28 de julio, podemos señalar el hecho, desde mi punto de vista decisivo de que durante esos diez dias las otras tres principales potencias habian movido ya. En primer lugar, Francia, que en menos de una semana habia sido capaz de mostrar impúdicamente al mundo todas sus contradicciones y debilidades: Blum decide, primero, atender a la petición de armas, absolutamente legal, de un gobierno, por añadidura, amigo; pero pronto, en función de consideraciones de orden interior e internacional, hace marcha atrás; y el 25 de julio se decide «no intervenir de ninguna manera en el conflicto interior de España» ${ }^{3}$. Esa misma noche Hitler decidía su primera ayuda a los rebeldes ${ }^{4}$. No pretendo afirmar con esto que hubiera necesariamente una relación de causa a efecto entre la retracción francesa y el paso adelante de Alemania, ni tampoco analizar aquí las razones últimas del paso dado por Hitler, pero si quisiera señalar la existencia de un nexo de unión entre las actitudes francesa y alemana. Se trata, evidentemente del anticomunismo, el miedo a la revolución, que si en Alemania era operativo en sí mismo, en Francia dictó la histérica, pero efectiva, reacción de la derecha francesa ante las intenciones de Blum de socorrer a la República ${ }^{5}$.

2 Expecialmente clarificador al respecto es el telegrama remitido por Ciano al consul italiano en Tánger el dia 27 de julio. En él afirmaba que 12 aviones y un barco cargado con material bélico estaban dispuestos para su envío a Melilla. Pero añadía: «Prenda ancora contatto con Franco e, senza assumere impegni o far promesse di sorta, cerchi di conoscere la esatta situazione attuale e se ancora vi é l'urgenza delle forniture richieste». De modo que sólo el día 28, tras conocer la perentoria respuesta de De Rossi, se tomó la decisión definitiva. Ciano a De Rossi, t. $3464 R / 57$ y t. 3488 R/60. Archivio Storico del Ministero degli Affari Esteri (ASMAE), Spagna Fondo di Guerra (SFG), b(usta) 5.

${ }^{3}$ Documents Diplomatiques Français (DDF), III, n. ${ }^{\circ} 17,25,33$ y 34 . Renouvin, P., «La politique extérieure du premier gouvernement Léon Blum", en AA.VV., Léon Blum chef du gouvernement 1936-1937. París, Armand Colin, 1967; PIKE, D.W., Les francais et la guerre d'Espagne. Paris, P.U.F., 1975; WARNER, G., «France and Non-Intervention in Spain, July-August 1936», en International Affairs, n. ${ }^{\circ} 38$, Abril, 1962, págs. 203-220; CARLTon, D., «Eden, Blum, ant the Origins of Non-Intervention", en Journal of Contemporary History, VI, 3, 1971, págs. 40-55; Gallagher, M.D., «Léon Blum and the Spanish Civil War» en Idem., págs. 56-64; STONE, G., «Britain, Non-Intervention and the Spanish Civil War» en European Studies Review, IX,1979, págs. 129-149; Duroselle, J-B., La décadence, 1932-1939. París, Dalloz, 1981.

${ }^{4}$ Viñas, A., La Alemania nazi y el 18 de julio, Madrid, Alianza, 1977 (2a.); ABEndRoth, H.H., Hitler in der spanischen Arena. Paderborn, Schöning, 1973; SмrтH, D., «Reacción refleja: Alemania y el comienzo de la guerra civil española», en Preston P. (ed.). Revolución y guerra en España 1931-1939. Madrid, Alianza, 1984, págs. 205-220; WheALEY, R.H., Hitler and Spain. Kentucky, University Press, 1989.

${ }^{5}$ El tono extraordinariamente crispado y violento de la prensa alemana sorprendió a Francois Poncet, embajador francés en Berlin, quien llegaba a preguntarse acerca de los 
Aunque Mussolini sabía que los sublevados en España estaban gestionando la ayuda alemana, y es posible que este hecho tuviera alguna incidencia en su decisión, no se ha podido demostrar que conociese la respuesta afirmativa del Führer a los enviados de Franco. Sí conocía Mussolini, en cambio, como se verá más adelante, la firmeza de la decisión francesa de no intervenir en España, circunstancia que sin duda debió pesar bastante en su decisión final. Creo, no obstante, que la potencia cuya actitud pudo condicionar más la decisión italiana fue Inglaterra.

Fijando por un momento nuestra atención en este último aspecto, la paradoja (o, si se prefiere, la dificultad) del problema estriba en el hecho de que Inglaterra no tomó ninguna decisión "positiva", en el sentido de la definición pública de una política determinada, de acción, en alguno de los sentidos posibles. Es decir, no movió. Y, sin embargo, ese no mover constituyó una señal inequívoca para las otras potencias.

¿Cuáles eran las señales que Londres emitía y que, en mi opinión, tuvieron un carácter decisivo al menos para Roma? En primer lugar, la desaprobación tácita (si no expresa) de la original decisión francesa de ayudar a la República ${ }^{6}$; en segundo lugar, «pequeños" pero muy significativos actos de hostilidad hacia la España republicana en Tánger y Gibraltar; en tercer lugar, aunque se tratase en este caso de una señal absolutamente pasiva e involuntaria, la voluntad franquista, rebelde, perfectamente conocida por Mussolini, de contar entre sus amigos con Inglaterra, Italia y Alemania ${ }^{7}$. Pero había algo más importante que todo ello y es, precisamente, lo que había debajo, la razón que estaba en la base de toda esa política que no era otra que el anticomunismo, la prevención antirrevolucionaria, unida a la convicción de que una victoria republicana daría paso inevitablemente al comunismo en España, que, a partir de

motivos reales de tan bien orquestada campaña, DDF, s.2, III, n. ${ }^{\circ} 10,22,28,39$ y 45. La misma obsesión anticomunista percibió Vansittart, Subsecretario permanente del Foreign Office, por entonces de visita en Alemania, Documents on British Foreign Policy (DBFP), $s$. 2, XVII, n. ${ }^{\circ} 58,63$ y, Apéndice, 1.

${ }^{6}$ No se trata de incidir aqui en el ya largo debate acerca de la incidencia real de las más o menos explicitas presiones inglesas para que Blum renunciase a sus iniciales propósitos de ayudar a la República. Pero sí de recordar que la percepción italiana del momento era que esas presiones habian existido realmente. Percepción, que por cierto, era compartida en otras capitales como Washington. Cerruti, t. 465, 15-VII-36, ASMAE, SFG, b. 6; Foreign Relations of the United States, 1936, II, págs: 447-449.

${ }^{7}$ Recuérdese la autorización extendida por Franco a Bolin $-\mathrm{y}$ mostrada por este a Mussolini- para "gestionar en Inglaterra, Alemania o Italla" la compra de armas. Cfr., Bolin, L., España los años vitales. Madrid, Espasa-Calpe, 1967, pág. 67. 
aqui, podria extender sus tentáculos hacia Portugal, Francia, etc. ${ }^{8}$. Se trataba de un mensaje que no era emitido explicitamente por el Foreing office pero que actuaba poderosamente en su interior con no menor fuerza de cuanto lo hacía, aquí sí públicamente, en los medios conservadores. Por tal motivo dicho mensaje pudo constituirse en el más efectivo y revelador, pese a su carácter «involuntario», de cuantos se emitían desde Londres ${ }^{9}$.

Todas estas señales fueron perfectamente captadas por Roma que pudo pensar en función de ellas que el riesgo de una airada reacción por parte de Londres a una moderada y discreta, aunque decisiva, ayuda a los rebeldes era prácticamente inexistente. La confirmación de que todos estos factores eran conocidos y operativos en Roma la encontramos en el hecho de que los diplomáticos italianos — desde Vitetti, encargado de negocios en Londres, hasta el propio Ciano- adoptaron ante los británicos no la posición del que debe justificarse por su ayuda a los sublevados, sino la del que no termina de entender por qué el Reino Unido no adoptaba abiertamente la misma posición ${ }^{10}$.

Naturalmente, todo lo dicho tendria escasa importancia si Mussolini hubiese sido indiferente a la actitud de Londres. Sucede, sin embargo, que no sólo no era así, sino que acaecía justamente lo contrario. Es decir, en la primavera-verano de 1936 la aproximación a Inglaterra era un axioma tan fundamental en la politica exterior fascista como su acercamiento a Alemania. La historiografía ha valorado en dos formas diferentes los cambios que se producen en el gobierno italiano en junio de 1936 y, más específicamente, la significación de la llegada de Ciano al Ministerio de Asuntos Exteriores. Para unos, tales hechos deberian valorarse como el triunfo de una línea abiertamente progermana. Para otros, estaban lejos de suponer un elección definitiva de campo. De Felice, concretamente,

${ }^{8}$ Cfr., especialmente, Moradiellos, E., Neutralidad benévola. Oviedo, Pentalfa, 1990; también, LITTLE, D., Malevolent Neutrality. The United States, Great Britain, and the Origins of ther Spanish Cicil War. Ithaca, Cornell University Press, 1985; EdWARDS, J., The Britis Government and the Spanish Civil War. Londres, Macmillan, 1979.

${ }_{9}$ Debe recordarse en este punto la clarividencia de Francois Poncet al analizar la campaña de la prensa alemana en relación a España y las paralelas atenciones que Vansittart estaba recibiendo en Berlín: "Cree --El gobierno nacionalsocialista- que los acontecimientos de España van a impresionar a los conservadores ingleses y, abriéndoles los ojos a la realidad del peligro bolchevique y a los riesgos de una amistad demasiado estrecha con una Francia ya contaminada, les separán de nuestro país. Está colmando de atenciones a Sir Robert Vansittart, de visita ahora en Berlín, y sigue abrigando la esperanza de que las circunstancias están favoreciendo un acercamiento anglo-alemán». Cfr. DDF, s. 2, III, n. ${ }^{\circ} 88$.

${ }^{10}$ Vitetti a Ciano, R. 2441/64), 29-VII-36, ASMAE, SFG, b.3, donde refiere su conversación con el jefe del grupo conservador en los Comunes, David Margesson. Véase, también, SAZ, Ismael: Mussolini..., op. cit., págs. 204-205. 
sostiene que se trataba fundamentalmente de un cambio en la jerarquía de los valores atribuidos por Mussolini a las distintas potencias. Así Francia pasaría a ocupar el último lugar dentro de esa jerarquía, mientras que Alemania empezaría a desempeñar un papel mucho más dinámico como baza a jugar en lo que constituiría el objetivo básico de su política exterior en aquellos momentos: la negociación de un acuerdo general sobre el Mediterráneo con Inglaterra ${ }^{11}$. En mi opinión, ambas cosas eran parcialmente ciertas. Es decir, Italia estaba dispuesta, efectivamente, a jugar la carta de Berlín para entenderse con Inglaterra. Pero ese entendimiento habría de ser necesariamente provisional a la espera de que los tiempos y condiciones madurasen para el inevitable enfrentamiento final; un enfrentamiento al que Italia debía comparacer necesariamente en alianza con Alemania. Al contrario de lo que pudiera parecer, esta percepción del "momento final» hacia aún más necesaria la aproximación a Londres. En efecto, un acercamiento a Berlin como el que se había producido en los primeros meses de 1936, no contrapesado por la paralela aproximación a Londres podria suponer la pérdida de la libertad de movimientos de la política exterior fascista y una precipitada subordinación de la misma a Alemania.

De ahi la ansiedad mostrada por la diplomacia italiana por el mencionado acuerdo con Inglaterra y la escasa entidad aparente de sus aspiraciones: el levantamiento de las sanciones, pasos significativos en la dirección del reconocirniento del imperio italiano en Etiopía y la aceptación por los británicos de que el Mediterráneo no podía ser ya un mar de su exclusiva propiedad, era casi todo lo que Mussolini pedía en aquellos momentos a Inglaterra.

Significativamente, los cambios experimentados en la orientación de la política exterior británica en torno al mes de julio de 1936 eran perfectamente complementarios de los de la italiana. Inglaterra precisaba, en efecto, de la colaboración del país transalpino para el nuevo acuerdo general europeo, el "nuevo Locarno" que debía suceder al que la reciente remilitarización de la Renania teriminaba de sepultar ${ }^{12}$. Pero necesitaba además otra cosa. Necesitaba borrar con la mayor rapidez posible a Italia

${ }^{11}$ Cfr., De Felice, R., Mussolini il duce. II. Lo Stato totalitario, 1936-1940. Turín, Einaudi, 1981; en un sentido similar, Quartararo, R., Roma tra Londra e Berlino. La politica estera fascista dal 1930 al 1940. Roma, Bonacci, 1980; para la opinión contraria, Petersen, J., Hitler e Mussolini. La difficile alleanza. Bari, Laterza, 1975; у D'AмоJA, F., La política estera dell'Impero. Padua, CEDAM, 1961.

${ }^{12}$ En cierto sentido el «nuevo Locarno" fue la primera víctima de la guerra de España. Posibilidad que no parecia contemplar David Margesson cuando, con fecha 1 de agosto, escribia a Chamberlain: «una victoria de los rebeldes en España y una reunión con éxito 
de la lista de potenciales enemigos. Los fundamentos de esa necesidad los conocemos perfectamente: el Imperio no podría soportar una guerra simultánea en tres frentes, de modo que el grueso de la capacidad defensiva británica debia reservarse para los más poderosos: Alemania y Japón. Precisamente en relación a este último era absolutamente vital que el Mediterráneo - arteria fundamental del Imperio- permaneciera tranquilo y ello exigia la amistad con Italia ${ }^{13}$. El problema estribaba en que para conseguir ese objetivo, en lo sucesivo básico de la política exterior británica, Inglaterra tenía muy poco que ofrecer. Así, por las mismas fechas en que se señalaba la necesidad de la aproximación a ltalia los Jefes de Estado Mayor subrayaban que el Imperio británico no podía permitir ninguna ulterior expansión del poder italiano en el Oriente Medio que pudiese amenazar los intereses, la seguridad o incluso el prestigio británico en la zona ${ }^{14}$. En resumen, el Mediterráneo era tan absolutamente vital para la defensa del Imperio que exigía una recuperación de Italia; pero ese mismo carácter vital hacia imposible que se le hiciesen concesiones significativas.

Así las cosas no es difícil deducir cual era el terreno en el que el encuentro buscado por ambas partes podía producirse que no era otro que el trazado por Mussolini: pasos en la dirección del reconocimiento del Imperio italiano y una más o menos vaga declaración de mutuo reconocimiento de los respectivos intereses en el Mediterráneo. Algunos pasos en la primera dirección se estaban dando efectivamente en el verano de 1936. Recordemos dos de ellos que, dado el momento en que se producen, nos interesan especialmente: el levantamiento de las sanciones se hizo efectivo el 15 de julio y el 27 del mismo mes Eden comunicaba a los Comunes la decisión de cancelar la entente mediterránea con Grecia, Yugoslavia y Turquía. Un paso que Mussolini había señalado días antes, en una entrevista al Paris-Soir como condición imprescindible para reemprender la política de colaboración internacional con Inglaterra ${ }^{15}$.

Tales eran, en efecto, las estrechas bases del entendimiento ansiosamente buscado por ambas partes. Unas bases ciertamente frágiles pero a las que, precisamente por ello, ambas estaban dispuestas a aferrarse. $Y$

de las potencias de Locarno sería magnifico». Cit. en Edwards, J., The British.., op. cit., pág. 99 .

${ }^{13}$ Chiefs of Staff Sub-Committee, 29-VII-36, FO371/20383 R4650/214/67. Donde se señala la importancia fundamental de restaurar las anteriores relaciones amistosas con Italia, añadiéndose que no se debería adoptar ninguna acción susceptible de poner en peligro dicho objetivo.

${ }^{14}$ Chiefs of Staff Sub-Committee, 13-VII-36, FO371/19910 C5356/4/18.

${ }^{15}$ Ingram a Eden, Roma, 24-VII-36, DBFP, s. 2, XVII, n. ${ }^{\circ} 13$. 
no habría de ser precisamente un acorralado gobierno republicano en España, en cuyo desprecio ambas rivalizaban, el que fuese a destruirlas.

La pregunta que podemos hacernos ahora, una vez vista la dinámica de las relaciones italobritánicas en el verano de 1936 es ésta: ¿habria arriesgado Mussolini en tales condiciones un paso en el Mediterráneo susceptible de interrumpir ese proceso de acercamiento? La respuesta habrá de ser, creo yo, negativa. Y más negativa aún habría de serlo si consideramos la eventualidad de que la reacción de las potencias democráticas ante los acontecimientos de España hubiese consistido en legitimar con su actitud al gobierno legítimo de España. Pero hicieron justamente lo contrario, de modo que la República española había venido a encontrarse, en forma tan sorprendente como rápida, internacionalmente aislada. Lo que obviamente vino a multiplicar el margen de maniobra de las potencias fascistas.

El proceso que conduce a la decisión mussoliniana de apoyar a los sublevados, desde la inicial negativa a las primeras peticiones de ayuda de Franco hasta el propio carácter cauteloso y progresivo de dicho proceso, subrayan la importancia de los factores apuntados.

Tenemos recreado así uno de los dos pies en que se apoyó el cambio de actitud italiana. ¿Cuál era el otro? El otro venía constituido por la evolución de la situación en España en términos, además, muy sencillos. Como demuestra la documentación italiana de la primavera de 1936, Mussolini y sus diplomáticos en España habían perdido toda confianza en la capacidad de las derechas españolas para imprimir ningún giro decisivo a la situación por medios legales o ilegales que fuere. Además el recuerdo de agosto de 1932 y la presencia de Azaña a la cabeza de la Administración republicana vendrian a corroborar esta falta de confianza. A la inversa, la documentación italiana correspondiente a los días sucesivos al 18 de julio, especialmente los telegramas cruzados entre Ciano y el cónsul en Tánger, De Rossi del Lion Nero, demuestra que las posibilidades de éxito de la sublevación constituían una preocupación central de las autoridades fascistas. De modo que sólo cuando éstas llegaron a la convicción de que con su ayuda la victoria rebelde era altamente probable y que, al mismo tiempo, esa ayuda no iba a determinar peligrosas reacciones internacionales, se tomó la decisión definitiva ${ }^{16}$.

Tales fueron, en definitiva, los factores generales y tácticos, coyunturales, que permitieron la intervención. Pero ello no nos dice nada, o nos dice muy poco, acerca de las razones profundas de la misma. Unas ra-

${ }^{16}$ Véase más arriba nota $n .^{\circ} 2$. 
zones que sólo pueden ser rastreadas a través del seguimiento de la trayectoria anterior y, con todas las precauciones, también de la posterior. Seguiremos ambas, por comodidad expositiva, desde dos puntos de vista distintos pero, como se verá, más que complementarios, profundamente interrelacionados: el de los factores político-ideológicos y el de los que denominariamos político-estratégicos o de política de potencia.

Para trazar un cuadro de conjunto acerca de la importancia de los factores ideológicos en las relaciones hispano-italianas hay que remontarse necesariamente al periodo de la dictadura de Primo de Rivera. Una dictadura cuya misma existencia constituyó, por razones de prestigio y de política exterior, un dato favorable para el fascismo italiano. Por otra parte, las simpatías fascistas del "pequeño Mussolini» vinieron a reforzar dichos supuestos. En términos negativos, la caída de la dictadura española tuvo repercusiones no instrascendentes para el curso de la política interior italiana. Los italianos sabían que la de Primo no era una dictadura fascista, pero les bastaba con que el dictador fuese simpatizante del fascismo. De modo que sólo insistieron pública y estridentemente en el carácter no fascista de la dictadura española después de su caida. Entonces se le hicieron toda clase de críticas (falta de un partido digno de tal nombre; excesiva consideración hacia los viejos conservadores; carencia del «alma» revolucionaria; olvido de la juventud...), pero sobre todo una: no ser una auténtica dictadura (dictadura di burla, en palabras de Grandi). Es decir, se le reprochaba en definitiva no haber sido capaz de evitar su propia caida. $O$, dicho de otro modo, una férrea dictadura, difusamente fascista y vagamente corporativa, aunque no fuese stricto sensu fascista, hubiese sido suficiente desde este punto de vista ${ }^{17}$.

La República fue algo mucho peor. Venía ésta en la época del fascismo, justo cuando Mussolini acababa de proclamar la inevitabilidad de un futuro fascista o fascistizado para la humanidad, y además lo hacia organizándose según los "arcaicos» principios del 89 , como Mussolini vendría a señalar agriamente en sus Aforismi. Claro que la propia República podía ser el Kerenski español y, en este sentido, se abria una más que significativa vía de contacto con todos los conservadores europeos y no europeos ${ }^{18}$. Pero para Mussolini, este era solamente uno de los pecados, el otro, el de ser liberal-democrática no era menor, aunque la importancia

17 Tusell, J. y SAZ, I., «Mussolini y Primo de Rivera: Las relaciones politicas y diplomáticas de dos dictaduras mediterráneas" en Boletín de la Real Academia de la Historia, $\mathrm{n}$. 79, 1982, págs. 413-483. Véase también Palomares Lerma, G., Mussolini y Primo de Rivera. Politica exterior de dos dictadores. Madrid, EUDEMA, 1989.

${ }^{18}$ Los Aforismi de Mussolini en Archivio Centrale dello Stato, Segretaria particolare del 
de este factor en la actitud mussoliniana tardará en ser apreciada por los conservadores europeos.

Lejos de lo que han querido demostrar algunos autores ${ }^{19}$, la actitud del «duce» hacia la II República a lo largo de sus cinco años de existencia subraya la importancia del factor antidemocrático sobre el meramente anticomunista. No sólo y no tanto por la colaboración con los conspiradores en agosto de 1932, o la subvención concedida a Primo de Rivera en la primavera de 1935, cuanto desde el de los mismo acuerdos de marzo de 1934 en Roma. En esta fecha, como demuestran todos los testimonios contemporáneos, Mussolini no apoyó a los conspiradores monárquicos a pesar de la existencia de un gobierno de derechas, sino porque los vencedores de las elecciones de 1933 no habian aprovechado su victoria para destruir la República, para destruir la democracia ${ }^{20}$.

Tras octubre de 1934, se lamentará la incapacidad de los fascistas españoles para hacer otra cosa que recoger algunos cubos de basura o llevar en sus flamantes automóviles a algunos militares. Después, se aceptará como un mal menor las garantías que contra la revolución ofrecían los gobiernos españoles de 1935 que, por otra parte, podían adoptar (y adoptaron) una actitud favorable respecto del conflicto etiópico. Finalmente, ya en 1936, se perderá como apuntábamos más arriba toda confianza en la derecha española.

Cuando esa desconfianza desaparezca, tras el 18 de julio, Mussolini se complacerá en mostrar su odio hacia las figuras liberales «arrepentidas», como Alcalá Zamora o Marañón, desde las páginas de // Popolo d'Italia (Era otra vez, como siempre, el Mussolini de los Aforismi).

Si la trayectoria anterior al 18 de julio demuestra la importancia de las consideraciones ideológicas en la actitud de Mussolini hacia España -y lo mismo permiten suponer sus "desfogos" posteriores-, no hay razón para suponer que dichos factores no fuesen operantes en el momento de la decisión. $O$, por lo menos, no hay indicio alguno de que así fuese. La única prueba que se ha aducido para justificar la preeminencia de los

duce (1929-1943), Autografi del Duce (1931), b.6; para la actitud de los medios conservadores y diplomáticos anglosajones hacia la República, LITTLE, D., op. cit.; sobre la vigencia del paradigma Kerenski en los medios británicoss, Moradiellos, E., op.cit., págs. 117 ss.

${ }_{19}$ Cfr., Coverdale, J. F., La intervención fascista en la Guerra Civil española. Madrid, Alianza, 1975, pág. 63; DE FELICE, R., Mussolini il duce, 11..., op. cit., págs. 360 ss.

${ }^{20} \mathrm{SAZ}, \mathrm{l}$., Mussolini..., op. cit., págs. $74 \mathrm{ss}$. Esta visión del duce era plenamente compartida por su embajador en España, Guariglia, quien consideraba que el éxito de la derecha en las elecciones de noviembre se habria malgastado por la excesiva prudencia, cuando no algo peor, de Gil Robles. GuarigliA, R., Primi passi in diplomazia e rapporti dall'Ambasciata di Madrid, 1932-1934. Napoles, 1972, pág. 345. 
factores estratégicos, la entrevista Goicoechea-Ciano del 25 de julio y el supuesto recuerdo de la vigencia de los acuerdos de marzo de 1934, está construida -como creo haber demostrado- sobre una auténtica falsificación ${ }^{21}$. Por lo demás, no hay porque dudar - al menos en este punto- en el relato de Bolin acerca de la incidencia en Ciano de los factores anticomunistas; ni parece lógico que las autoridades fascistas estuviesen menos preocupadas por la amenaza revolucionaria en España, en el Mediterráneo, que los sectores conservadores de todo el mundo.

Las dudas acerca de la importancia creciente dei factor ideológico en la progresiva intervención italiana en España son todavia menores. Es evidente que el propio sentido antifascista dado a su lucha por -permitáseme la redundancia - los antifascistas españoles tuvo una incidencia más que notable en Mussolini; como la tuvo aún en mayor medida el hecho de que esta óptica fuese progresivamente adoptada por cada vez más amplios sectores inicialmente ajenos a ella.

Pero no es necesario alejarse de la propia Italia para captar ese papel creciente del factor ideológico. Bastaría en este sentido recordar la naturaleza y las razones de los sectores que apoyaban la intervención en España: fuera del partido, los católicos, ganados por el carácter «religioso" de la guerra de España; dentro del partido, los moderados que querian dar a la intervención un sentido próximo a la de los anteriores y pensaban que este planteamiento podría influir también en la dinámica interna del régimen; pero también el sector más radical e intransigente del partido apoyaba la intervención y justo por la razón contraria, es decir, para afirmar el peso del propio partido frente a los sectores conservadores. En sentido similar, la Milicia apoyaba una intervención que habria de ser para ella «una guerra fascista» en revancha al mayor protagonismo desempeñado por el ejército en la guerra de Etiopia ${ }^{22}$. Por el contrario la marina - el arma más conservadora y filobritánica- adoptaba una actitud de mal disimulada oposición y, sin llegar a tanto, el ejército parecía contentarse con cumplir. Solo la "aeronáutica», el arma más claramente fascistizada, aceptó con entusiasmo sus nuevas obligaciones en España ${ }^{23}$.

No parece, finalmente, que un Mussolini obsesionado por aquellas fechas por los problemas ideológicos, pudiera permanecer inmune a la llamada de estos factores. Máxime si tenemos en cuenta que la guerra de España coincide con la svolta totalitaria del régimen. Una svolta carac-

${ }^{21} \mathrm{SAz}$, I., Mussolini..., op. cit., págs. 186-191.

${ }^{22}$ Cfr. de Felice, R., Mussolini il duce, II..., op. cit., págs. 375-381.

${ }^{23}$ Cfr. Ciano, G., Diario, 1937-1943. Milán, Rizzoli, 1980, pág. 29. 
terizada precisamente, entre otras cosas, por una dura polémica contra los sectores conservadores, contra el vivir tranquilo, «burgués», y en favor de una «ideologeización» de la vida de los italianos en la que el elemento belicista era central. También desde este punto de vista, pues, la intervención italiana en España parece perfectamente imbricada con la dinámica interna del régimen y su evolución político-ideológica.

Relacionado con lo anterior aunque no idéntico a él se plantea el problema del verdadero alcance de la intervención fascista en los asuntos internos de la España nacionalista. Creo que desde este punto de vista debe subrayarse la importancia de la llamada «misión Farinacci» llevada a cabo en un momento crucial para la evolución política de la «España nacional». Pues bien, valdría la pena recordar que el objetivo fundamental de tal visita consistía en recomendar la creación de un Partido nacional, único, fuerte, autoritario y totalitario encabezado por Franco. No hay duda de que tal recomendación fue plenamente aceptada, aunque es posible que coincidiera ya previamente con los propios deseos de Franco. Seguramente es esto lo que entendía Mussolini cuando informaba a Cantalupo acerca de sus aspiraciónes de fascistizar España. Claro que el propio Cantalupo se ocupó de confundir a tirios y troyanos haciendo desaparecer de su posterior libro tan significativa referencia a las intenciones de Mussolini ${ }^{24}$.

Es cierto, por otra parte, que Mussolini nunca presionó para que se concediera más poder al sector especificamente fascista de la alianza contrarrevolucionaria española. Pero tal constatación dice, al contrario de to que habitualmente se supone, bien poco. En primer lugar, porque tal sector, en la Salamanca de la primavera del 37, estaba lejos de constituir un ejemplo de coherencia. Farinacci, en concreto, le dirigiría tres reproches fundamentales: buscar un acuerdo con los tradicionalistas que sólo beneficiaba a estos últimos y sus pretensiones monárquicas; constituir una fuerza sospechosa por la masiva incorporación a él de elementos «rojos» en las zonas «liberadas»; y trabajar en detrimento de Franco ${ }^{25}$. En segundo lugar, porque las simpatías dominantes en ese sector por el más radical y "puro» modelo alemán no constituían el mejor augurio para Mussolini. Tampoco cabe descartar, finalmente, que en Roma se temiese el surgimiento en España de un propio y verdadero Estado fascista, lo suficientemente fuerte, tal vez, como para desafiar la primacía ideológicopolítico-estratégica de la Italia fascista en el Mediterráneo. No es de extrañar, por tanto, que entre el afascismo dominante en algunos medios

${ }^{24}$ Cfr., SAz, I., Mussolini..., op. cit., págs. 221-222.

${ }^{25}$ Farinacci a Mussolini. Zaragoza, 8-IIl-37, ASMAE, SFG. b. 4. 
militares, la influencia de los medios monárquicos en Salamanca -también señalados por Farinacci-y la incoherencia y falta de dirección del sector falangista, Mussolini se reafirmara en lo que desde el principio había constituido su opción básica: la apuesta por Franco como cabeza indiscutida de un modelo de Estado bastante parecido al que iba a configurarse en los meses sucesivos.

En breve, Musolini no se conformó nunca con la destrucción de la amenaza comunista; ni siquiera con la aparición de una dictadura más o menos liberal. Aspiraba a ver surgir una dictadura suficientemente fascistizada como para caer dentro de su esfera de influencia político-ideológica, pero no «tan» fascista como para que pudiera situarse en un plano de igualdad.

Una de las razones barajadas por la historiografía para explicar/justificar la intervención italiana era que ésta habria venido dictada por un reflejo defensivo frente a Francia. En este sentido se han señalado fundamentalmente dos tipos de consideraciones. En primer lugar, la supuesta precedencia de la ayuda francesa a la República, o la desconfianza en que el cambio de actitud adoptado por el gobierno francés el 25 de julio fuese real. Hoy en día, sin embargo, como creo haber demostrado ampliamente, esta tesis es indefendible. No sólo porque Francia efectivamente paralizó los convoyes que transportaban las armas para la República, sino, fundamentalmente, porque Roma estaba perfectamente informada de ello a través de su embajada y consulados en Francia que, a la sazón, habian montadc un eficaz sistema de control y verificación ${ }^{26}$.

La otra consideración a que nos referimos es la supuesta existencia de un pacto secreto hispano-francés que permitiera el paso de las tropas coloniales francesas a través de territorio español. También ésta es fácilmente refutable. Los despachos del embajador italiano en Madrid, Guariglia, en el otoño de 1932 a propósito de la visita de Herriot, y las informaciones del propio Goicoechea en 1935, habian confirmado a Roma que tales pactos no habían existido nunca. Es más, para colmo de las paradojas, el único pacto firmado por España que afectaban a Italia y estaba en vigor era el Tratado de arbitraje y conciliación hispano-italiano de 1926 que terminaba de ser tácitamente renovado en junio de 1936.

Todo ello no quiere decir que el reflejo defensivo antifrancés fuese absolutamente inexistente. Una victoria republicana podía venir a fortalecer los vínculos entre los gobiernos español y francés, reforzándose así la sensación de aislamiento postetiópico que se vivía en Roma. De hecho,

${ }^{26}$ Cfr., Saz, I., Mussolini..., op. cit., págs. 196-201. 
la ansiedad del gobierno italiano ante la posibilidad de verse confrontado con gobiernos en Francia y España en los que los comunistas y antifascistas pudieran ser predominantes podía constituir una solapada exposición de dicho temor ${ }^{27}$. Es posible que así fuese, pero no estará de más recordar que también en este caso las preocupaciones italianas coincidian casi punto por punto con las británicas. Piénsese, si no, en el crucial Memorandum del Foreign Office en el que se señalaban dos líneas de actuación a seguir en relación con la guerra civil española: 1. impedir por las buenas o por las malas que Francia se volviera bolchevique bajo la influencia de la guerra civil española; y 2. liberar a ltalia del sentimiento de aislamiento y vulnerabilidad en el que la habría dejado el contencioso de Abisinia ${ }^{23}$. A la luz de este tipo de valoraciones estaríamos tentados de afirmar que estos eran justamente los términos en los que Londres estaba dispuesto a racionalizar-justificar-permitir la intervención italiana en España ${ }^{29}$.

La innegable existencia de preocupaciones defensivas que, sin embargo, podían haberse visto notablemente mitigadas por el conocimiento de la nueva postura inhibicionista francesa, no puede utilizarse en modo alguno como coartada para ignorar la entidad de las abiertamente ofensivas. Porque estas últimas, en efecto, a diferencia de las anteriores, tienen una presencia y operatividad absolutamente indiscutibles. Al igual que ocurría con las motivaciones político-ideológicas, la trayectoria anterior y también la posterior de las relaciones bilaterales hispano-italianas ofrece evidencias abrumadoras. Recien proclamada la dictadura de Primo de Rivera, Mussolini acarició la idea, tan ambiciosa como disparatada, de concluir un tratado político-militar con España, dirigido contra Francia y capaz de inquietar a griegos, sudamericanos y a la opinión pública internacional. Como decíamos el proyecto era absolutamente disparatado y chocaba frontalmente con la debilidad de ambas dictaduras en el escenario internacional, de modo que la realidad terminó por imponerse $y$ todo quedo en el inocuo tratado de Arbitraje y Conciliación de $1926{ }^{30}$.

Sin embargo, la ambición demostrada por Mussolini en aquella ocasión no era, ni mucho menos, flor de un día. Es cierto que durante la II

${ }^{27}$ Ingram a Eden. Roma, 28-VII-36, DBFP, ss. 2, XVII, n. ${ }^{\circ} 28$.

${ }^{28}$ Memorandum de Sargent, 12-VIII-36, FO 371/20534, W9331/62/41.

${ }^{29}$ Como se sabe, la percepción del sentimiemto de aislamiento como movil de las actitudes italianas en la primavera-verano de 1936 estaba bastante generalizada. Recordemos, a título de ejemplo, que ese era un punto básico en los análisis de los embajadores soviético y japonés en Roma. Ambos creian, también, que los acontecimientos de España podian tender a reforzar aquella sensación. Ingram a Eden, 3-VIII-36 y 12-VIII-36, FO 371/20417 R4830/341/22 y FO 371/20424 R4946/3928/22.

${ }^{30}$ Tusell, J., y SAZ, I., «Mussolini y Primo de Rivera...”, op. cit., págs. 442-445. 
República las preocupaciones defensivas, como hemos visto, dominaron. Pero eso era inevitable en el contexto de la existencia en España de un régimen democrático. Sin embargo, cuando se apostaba por subvertir el régimen las preocupaciones defensivas dejaban paso con facilidad a las ofensivas. Asi en los acuerdos de marzo de 1934 Italia se comprometia a garantizar el statu quo en el Mediterráneo occidental, pero, notese la salvedad, sólo en lo que afectaba a los «derechos territoriales de España, tanto de soberanía como de protectorado». El tratado de neutralidad y amistad que posteriormente habria de firmarse con el nuevo gobierno español habría de ser, consecuentemente, algo más que defensivo. En realidad los acuerdos de marzo de 1934, firmados con un grupo de conspiradores, contienen en esencia al que el 28 de noviembre de 1936 se firmaria, con carácter secreto, con el general Franco. Un tratado que, como bien señalara Santarelli, constituía una completa hipoteca sobre España. Véase, si no, el siguiente párrafo correspondiente al artículo 4 . del tratado ${ }^{31}$ :

«En caso de que una de las partes contratantes se encuentre implicada en un conflicto con una o más Potencias, o si se aplican medidas colectivas de carácter militar, económico o financiero contra cualquiera de las partes, el otro Gobierno se compromete a adoptar hacia el primero de los Gobiernos mencionados una actitud de neutralidad benévola, garantizarle los suministros necesarios, poner a su disposición todas las facilidades, la utilización de puertos, de líneas aéreas, de ferrocarriles y de carreteras, así como a mantener relaciones comerciales indirectas».

Por lo demás ello era plenamente acorde con las multiples manifestaciones de Ciano y Mussolini durante aquellos años acerca de lo que esperaban de la victoria de Franco: adhesión de España al pacto Antikomintern (Mussolini 1937); utilización de las bases de Mallorca contra Francia (Mussolını 1937); alianza con España (Mussolın 1939). En definitiva, se trataba de poner (se habrian puesto) con la guerra de España «las verdaderas bases del Imperio Mediterráneo de Roma» (CIANO 1939); o, en palabras de Mussolini, también en 1939, de conseguir el libre acceso al Océano.

Lo que nunca pretendió Mussolini fue la adquisición de ningun parte de territorio español. Ese fue siempre un falso problema que no sirvió sino para enmascarar la trascendencia de los objetivos reales, que a fuer de ser más reales eran también mucho más ambiciosos.

${ }^{31}$ El texto del acuerdo puede verse reproducido en COVERDALE, J., La intervención..., op. cit., págs. 367-369. 
Digamos de paso que en el contexto de esta mayor ambición debe encuadrarse la tradicionalmente subrayada generosidad económica de Mussolini hacia los nacionalistas españoles. Una España amiga y aliada valía mucho más que unos millones de pesetas o una política de maneras fuertes o imposiciónes como la llevada a cabo por Alemania. Desde 1923 hasta 1936 la preocupación por los problemas económicos es constante - lo que no quiere decir que fuese la principal-y sus objetivos ambiciosos: una abierta colaboración económica que abriría las puertas de España a la penetración del capital italiano. Al contrario de lo que sucede con la generosidad italiana en lo que al pago de la deuda se refiere, ampliamente estudiado y convincentemente demostrado, este otro aspecto está esperando todavia un estudio ${ }^{32}$. Con todas las precauciones necesarias me atrevería a recordar aquí la extraordinaria fortuna encontrada en la España franquista por empresas como la Pirelli, la Hispano-Olivetti o la Fiat.

A la luz de lo hasta aquí expuesto podemos volver a reconsiderar la situación de las primeras semanas de la Guerra Civil Española. Había una serie de elementos que desde el supuesto de una victoria de los rebeldes dejaban la partida abierta entre las potencias que directamente (Alemania e Italia) o indirectamente (Inglaterra) favorecian su causa. De ellas Alemania parecía conformarse con objetivos políticos básicamente negativos (dificultar la posición estratégica francesa) y apreciables ventajas económicas, sobre la base todo ello del reconocimiento de que España pertenecía a la esfera de influencia italiana. Existen pocas dudas, por otra parte, como Enrique Moradiellos acaba de recordar convincentemente de que el supuesto de guerra breve era esencial en esa primera fase para explicar la actitud inglesa y, también la de las demás potencias. La neutralidad benévola podía descansar desde este supuesto de la brevedad en la confianza de que su superioridad económica y naval podría neutralizar la eventual orientación filofascista de una agradecida España victoriosa. Por esa misma razón, la neutralidad no lo era sólo respecto de los dos bandos contendientes en la guerra civil española sino también, y ello debe subrayarse, respecto de la implicación con uno de ellos de las potencias fascistas ${ }^{33}$.

La obsesión anticomunista constituyó, sin duda, el trait d'union entre la actuación de unos (Italia y Alemania) y la permisividad de otros

\footnotetext{
${ }^{32}$ Sobre el pago de la deuda, véase VIÑAs, A. y otros, Política comercial exterior en España (1931-1975). Madrid, BEE, 1979, 2 vols., l, págs. 141-247.

${ }^{33}$ Cfr., Moradiellos, E., Neutralidad..., op. cit., págs. 225-226.
} 
(Inglaterra) ${ }^{34}$. Se trataba en cierto modo de la reproducción a escala internacional de las condiciones que a escala nacional habian favorecido el ascenso de los fascismos italiano y alemán. La gran industria, los agrarios y los sectores conservadores tradicionales habian permitido, favorecido $\mathrm{y}$, en su momento, apoyado el ascenso del fascismo desde la confianza en su capacidad para reabsorberlo, «fagotizarlo». En el caso de España, el riesgo limitado que suponia la participación italiana en la liquidación de la amenaza revolucionaria podría ser posteriormente reabsorbido por las grandes potencias liberalcapitalistas (especialmente Inglaterra) a través de mecanismos económicos y coercitivos.

El error de este tipo de valoraciones estribaba también en el mismo punto en que habia estribado en el marco nacional: el fascismo no era una fuerza destinada a ser subordinada. Enemigo radical del comunismo y defensor del modo de producción capitalista, conllevaba una voluntad no menos radical de transformación de las estructuras políticas, sociales y económicas, nacionales e internacionales. La preocupación italiana por el triunfo del comunismo en España era por lo menos tan genuina como la de los conservadores británicos o franceses. Sólo que Mussolini aspiraba además a fascistizar España, es decir a verla conformada como una dictadura totalitaria, de partido único, más o menos corporativa, filofascista y basada en el principio del caudillaje. No quería más -por ejemplo, un papel preeminente del partido fascista- pero tampoco menos.

Del mismo modo, Mussolini podía intentar romper el supuesto cerco y ailamiento posetiópicos con su intervención en España e intentar neutralizar asi el riesgo de una mayor identificación hispano-francesa. Desde este punto de vista, Inglaterra podía mostrarse benevolente, como si este fuese el «contentino» que habría que dar a los italianos para que no se rompiesen los puentes de la tan deseada reaproximación italo-británica. Mussolini, desde luego quería eso, pero también mucho más. Aspiraba a

\footnotetext{
${ }^{34}$ Una de las más claras, o, si se prefiere, cinicas, exposiciones de esta actitud la constituye una carta del influyente secretario del gabinete británico, Sir Maurice Hankey, a Eden en julio de 1937. Claro partidario de mejorar las relaciones con Italia, Hankey se lamentaba de que se siguiese sospechando acerca de las improbables ambiciones italianas o alemanas en Marruecos, Mallorca..., y se dudase, por el contrario, de las muy probablemente sinceras declaraciones de aquellos gobiernos en el sentido de que su apoyo a Franco tenia por único objetivo la lucha contra el comiunismo. Si el anticomunismo llevaba a muchos ingleses a desear el triunto de Franco, ¿por qué no iba a suceder lo mismo en forma infinitamente mayor en las potencias del Eje? Además - añadía Hankey- ¿no habian apoyado anteriormente británicos y franceses las revoluciones en Grecia, Sudamérica, Polonia o Bélgica?, ¿por qué no iban a poder hacerlo ahora los italianos? La conclusión de tan brillante razonamiento no se hacía esperar: "There is nothing new to history in the Italian attitude». Hankey a Eden, 23-VII-37, Birminghan University Library, Avon Papers (Eden), 13-1-42-44.
} 
conquistar un aliado que en clave antifrancesa, sí, pero llegado el momento también en clave antibritánica, cimentase las bases del Imperio Mediterráneo de Italia ${ }^{35}$.

La dinámica de la intervención italiana a lo largo de toda la guerra civil responde perfectamente a esta doble dirección. De una parte, en lo que era el objetivo máximo al cual habrian de subordinarse todos los demás, se trataba de asegurar la victoria total y absoluta de Franco. De otra, se trataba de no romper los puentes con Inglaterra, de modo que la guerra civil española no se convirtiese en un obstáculo insalvable para lograr aquel acuerdo general al que nos referiamos anteriormente. En la práctica ello suponía llegar siempre tan lejos en la ayuda a Franco como Inglaterra permitiese. Aunque, eso sí, moviéndose siempre muy cerca del límite, tanteando siempre en el terreno de los hechos donde se hallaba tal límite.

De tal dinámica hay que señalar desde el principio dos características que se demostrarian cargadas de consecuencias. En primer lugar, que la necesidad de buscar el acuerdo con Inglaterra seria un factor omnipresente para la aceleración y agudización del compromiso militar italiano en España. Así, por ejemplo, cada vez que razones políticas aconsejaban facilitar un acuerdo del Comité de No Intervención se incrementaba el apoyo bélico a fin de hacer de éste el esfuerzo final, el que garantizaria «definitivamente» la victoria de Franco y el que, por tanto, otorgaría a Mussolini los frutos de la victoria al tiempo que le liberaria de los costes

${ }^{35}$ El director del departamento del Sur del F. O., O'Malley, bastante propenso a ver la larga mano de Moscú en el origen de la guerra de España y de su internacionalización, no tenia ningún reparo en caracterizar la política británica como algo dictado por la imperiosa necesidad de «lograr la distensión con Italia» (Cfr. Moradiellos, E., op. cit., pág. 345). Esto no le impediría, sin embargo, realizar una acertada diagnosis acerca de los objetivos de Mussolini en España: la instauración de una nueva dictadura, lo que reforzaría sus propios principios, y debilitar, merced a las especiales relaciones a establecer con el dictador español, el poderío naval británico en el Mediterráneo. Memorándum de O'Malley, '8-X-36, FO 371/20425 R 6135/6165/22.

Ni una cosa ni otra habian variado significativamente a la altura del verano de 1937. Para entonces el mismo O'Malley apuntaba - y el Foreign Office suscribia - la necesidad de situar a Italia como probable enemigo, a partir, fundamentalmente, de la contradicción existente entre la voluntad de potencia italiana y el control por parte inglesa de las dos puertas principales del Mediterráneo (Memorándum de O'Malley, 1-VI-37, FO 371/21159 R3831/1/22). Pues bien, tras una compleja serie de discusiones en torno a este Memorándum el Consejo de Ministros llegó a la conclusión de que el mejor modo de hacer frente a la inquietante actitud italiana era mejorar las relaciones con Alemania. Pero lo más sorprendente es que para este último objetivo no se encontró mejor medio que el de evitar presentar en lo sucesivo las propuestas inglesas "respecto de España" como anglo-francesas, buscándose por el contrario una mayor contacto con Berlín a la hora de desarrollar tales propuestas. Cabinet Conclusions, 29 (37), 8-VII-37. 
de la intervención. Un buen ejemplo de ello lo constituye la aceleración de las primeras remesas de material en agosto de 1936 mientras se ganaba tiempo hasta la aceptación de la No Intervención; y lo mismo puede decirse de los envios masivos de material y hombres hasta febrero de 1937 ante la perspectiva de la próxima aceptación del plan de control ${ }^{36}$.

En segundo lugar, esa directriz esencial de la intervención italiana, consistente en la máxima aceleración del esfuerzo militar para acortar la duración del conflicto, constituiria una fuente de problemas con las propias autoridades nacionalistas: a veces porque se les presionaba para acelerar las operaciones; a veces porque se les pretendian imponer directrices de lucha y líneas de avance; a veces porque casi se llegaba a pretender sustituirlas en las grandes operaciones consideradas decisivas ${ }^{37}$.

Las consecuencias de todo ello eran lógicamente que Italia se involucraba cada vez más en el conflicto español; de modo que cada intento de acelerar los tiempos por salir de él venía a traducirse en un compromiso mayor. Ya hemos señalado que ello se debía a la existencia de un objetivo único irrenunciable cual era la victoria absoluta de Franco. Pero junto a esto habia otras circunstancias que "sorprendentemente" las autoridades fascistas parecian dispuestas a ignorar. $Y$ estas eran que el mundo no estaba formado exclusivamente por potencias fascistas, gobiernos conservadores y opinión anticomunista. Así la llegada de las brigadas internacionales y el apoyo soviético vinieron a encarecer la apuesta "forzando" un nuevo salto adelante en la involucración fascista ya en noviembre-diciembre de 1936; en el verano del 37 la existencia de supuestos envíos marítimos soviéticos condujo a la crisis de Nyon; la constitución en marzo de 1938 de un nuevo gobierno Blum facilitó una temporal apertura de la frontera francesa que obligó a nuevos esfuerzos compensatorios.

Es prácticamente imposible sobrevalorar la incidencia de todos estos factores sobre el desarrollo de la política exterior fascista. Guadalajara dio pie a campañas de prensa incluso en el Reino Unido, que además de llevar a Mussolini a los límites de su enfurecimiento, malogró todos los potenciales resultados obtenidos con el Gentlemens Agreement de Enero; Nyon supuso una debacle diplomática que hizo parecer incluso como posible un alineamiento de Londres con las posiciones de París; el nuevo esfuerzo bélico de la primavera-verano de 1938 -bombardeos italianos

\footnotetext{
36 Verbali della riunione a Palazzo Venezia del 14 Genaio 1937-XV (Goering), ASMAE, Gainetto, b. $3031 / 9$.

${ }^{37}$ Cfr., Saz, I. y Tussel, J., Fascistas en España. Madrid, CSIC, 1981, passim.
} 
de Barcelona y buques británicos incluidos- prácticamente neutralizó el alcance de los «acuerdos de Pascua».

Es verdad que a lo largo de este proceso los italianos obtuvieron también algunas victorias diplomáticas, pero no lo es menos que éstas no sólo serian pírricas, sino que además contribuirian a recrear falsas imágenes de la realidad. La más notable de tales victorias es sin duda la caida de Eden en febrero de 1938 que allanaría el camino para los acuerdos de Pascua. Ciertamente ello suponia la derrota de aquellos sectores del Foreign Office -y de los conservadores británicos- más claramente partidarios de que todo acuerdo con Italia debía conseguirse desde posiciones de fuerza y sobre la base de una clarificación definitiva de la situación de los italianos en España. Y en este sentido suponía también el triunfo de quienes, como Chamberlain, seguían considerando la cuestión española como un problema menor que «no valia» la pérdida de las posibilidades de llegar a un entendimiento con Italia ${ }^{38}$. Pero el espejismo estribaba en que ni siquiera la caída de Eden liberaba a Chamberlain de la presión de este sector, ni de la opinón pública británica. Así, el esfuerzo apaciguador de Chamberlain respecto de Mussolini no sirvió más que para recrear una y otra vez los dilemas a los que Eden se habia enfrentado en los años anteriores. De este modo los acuerdos de Pascua no entraron en vigor hasta después - y a consecuencia- de Munich. Es decir del hecho que marcaba claramente la pérdida «real» de la iniciativa italiana en Europa.

Dicho esto, me parece necesario subrayar que no tiene ningún sentido acusar a la politica británica de miope o falta de perspectivas. Tal política se desarrolló a partir de unos presupuestos y unos intereses reales, muchas veces contradictorios, que admitían diversas interpretaciones y que no es el caso juzgar aquí. El error, si en estos términos puede hablarse, habría estribado en todo caso en la incapacidad mussoliniana para captar

${ }^{38}$ La literatura ha subrayado acertadamente el papel de Grandi en el proceso que condujo a la ruptura Eden-Chamberlain. Vale la pena recordar, sin embargo, que en este aspecto la labor del embajador italiano encontró el más abonado de los suelos. Creo que la carta que en noviembre de 1937 escribia Sir Maurice Hankey a su hijo Robin, lo expone con clara precisión. Asi tras señalar que la amistad con Italia y Alemania proseguía por buen camino y que esa era también la opinión del primer ministro y de Cadogan, el secretario del gabinete añadia: "Anthony is the real obstacle. He hates Dictators so much that he seems to me unwilling to make a real effort». Según Hankey esta opinión negativa acerca de Eden sería compartida incluso por un amplio número de parlamentarios que se estarian interrogando acerca del empecinamiento de Eden en mantener la amistad con Francia en detrimento de Italia y Alemania. Maurice Hankey to Robin, 21-XI-37, Churchill College Library (Camdridge), Archives of Lord Hankey of the Chart, 3/42. 
que Inglaterra, como la propia Francia, eran potencias democráticas que no definian su política exterior en los términos de libertad personal que podía hacerlo el mismo Mussolini.

Desde otra perspectiva tampoco cabe hacer recaer excesivas responsabilidades sobre un supuesto maquiavelismo germano para conseguir la mayor involucración de Roma en los asuntos hispanos. Es verdad que Alemania fue la gran beneficiada del compromiso de Roma en España y que incluso estuvo interesada en que dicho compromiso se dilatara en el tiempo. $Y$ ello con el evidente fin de conseguir ampliar su margen de maniobra en Europa central mientras las potencias occidentales desviaban su atención hacia España. Pero no es menos cierto que fue Roma, y no Berlín, quien decidió autónomamente el ritmo y entidad de su compromiso en España. En cierto modo podría decirse incluso que fue la firme decisión mussoliniana de obtener importantes ventajas en España la que aconsejó a los germanos a dejar que también el protagonismo militar y los previsibles costes político-diplomáticos cayeran del lado italiano ${ }^{39}$.

La intervención italiana en la guerra civil fue con mucho la más importante y decisiva de cuantas tuvieron lugar, hasta el punto y esto debe quedar definitivamente claro de que sin ella la victoria de Franco habría resultado más que problemática. Cerca de 80.000 italianos combatieron en España, de los que casi 4.000 perdieron aqui su vida; 759 aviones, alrededor de 6.600 cañones, morteros y ametralladoras, 157 tanques, cientos de miles de fusiles y millones de proyectiles y cartuchos fueron enviados a España. En unos 8.500 millones de liras se cifró por parte italiana el coste económico de la operación, aunque esta cifra quedó reducida a 5.000 millones en el acuerdo final de pagos. Pero el aspecto cuantitativo de la cuestión es en cierto modo el menos relevante, al menos en términos comparativos. No debe minusvalorarse, en efecto, el hecho de que la relación entre los envios italianos y las necesidades inmediatas de la guerra tuvieron una relación directa incomparablemente mayor que la que pudo darse en el caso de las ayudas obtenidas por la España republicana. Por otra parte, la marina - submarinos especialmente- intervino en la guerra de España de tal modo que muchas de sus actuaciones pudieran considerarse intercambiables con las de la marina nacionalista. Más allá incluso de los suministros de material de la «regia aeronautica", aviones italianos llegaron a bombardear ciudades españolas desde sus bases en Italia. No menos decisivo resultó, en fin, el apoyo diplomático. Sin él y el paralelo de la Alemania nazi, difícilmente podia haber obtenido el bando franquista el reconocimiento internacional del

${ }^{39}$ Neurath a Hessel, 5-XII-36, GD, D, III, 142. 
que, mal que bien, gozó desde muy pronto. Antes de que ello sucediera la Italia fascista se convirtió en el mejor defensor en clave diplomática de los intereses nacionalistas.

Evidentemente, media un abismo entre las primeras reacciones italianas a los sucesos del 18 de julio y su compromiso final. Un abismo que no es otro que el que va de casi considerar la guerra de España como una guerra inoportuna, al de la práctica hipoteca de la política exterior fascista en los años sucesivos. La pregunta que debemos formularnos a partir de aquí es obvia: ¿hasta que punto el envite mereció la pena?

Para responder a ella hemos de tener en cuenta en primer término que uno de los objetivos fundamentales de la política italiana para España - el de ganar con ella un aliado o, en su defecto, neutralizar su eventual francofilia - no constituia a la altura de 1936 un elemento central de la política exterior italiana. Ahora bien, esa relativa marginalidad, estaba dictada en buena medida, como vimos, por razones de oportunidad que el propio surgimiento del conflicto empezó a mutar. Con el desarrollo del mismo la importancia en términos relativos y absolutos de España en el cuadro general de la politica exterior italiana no hizo sino crecer. $Y$ esta es una de las razones que, junto con las de orden ideológico y las consideraciones de prestigio, determinaron la decisión mussoliniana de apoyar a Franco hasta el final.

Planteada la cuestión en estos términos hay que reconocer que la intervención italiana en la guerra de España se saldó con un éxito sin precedentes, al menos sobre el papel. El tratado de noviembre de 1936 establecía unos vínculos entre los dos países que hacian de España algo más que un amigo accidental. Ya en 1939 había indicios suficientes para acreditar que Franco honoraría sus compromisos alineando su política internacional con la de las potencias del Eje (retirada de España de la Sociedad de Naciones y adhesión al pacto Antikomintern). Por eso mismo no ha de resultar extraño el optimismo con que Ciano y Mussolini valoraban en aquellos momentos el futuro de las relaciones hispano-italianas; ni que el mismo Mussolini empezase a concebir planes para un reparto entre españoles e italianos de las posesiones francesas en el norte de África ${ }^{40}$.

Desde el punto de vista político-ideológico la victoria del «Duce» no parecía menor. El comunismo, como el antifascismo y el liberalismo habían sido derrotados en España. El fascismo había conseguido, pues otra gran victoria, que por su misma dificultad y la carga ideológica mundial que el conflicto español había adquirido era tanto más valiosa. Además la España vencedora se estaba institucionalizando según unas líneas que

\footnotetext{
${ }^{40}$ Cfr., Tusell, J. y GarCiA, G., Franco y Mussolini. Madrid, Planeta, 1985, pág. 33.
} 
a Mussolini le resultaban enteramente gratas: El Fuero del trabajo, único texto hasta entonces constituyente del nuevo Estado se caracterizaba por sus notables semejanzas con la Carta del Lavoro; se había constituido un partido único de ideologia fascista bajo la única dirección del jefe del Estado; los elementos más claramente fascistas o fascistizados del entorno de Franco estaban claramente en ascenso. En resumen, parecian estar sentándose las bases del Estado totalitario.

Como veremos en seguida tan brillantes horizontes no estaban exentos de amenazadores nubarrones. Pero vale la pena señalar por el momento esa brillantez de perspectivas porque de lo contrario se corre el riesgo de establecer valoraciones precipitadas cuando se apunta al hecho, éste sí incontrovertible, de que al fin y al cabo, la carta española terminara por servir de bien poco a Mussolini.

¿Cuáles era aquellos nubarrones? En primer lugar que buena parte de las ventajas conseguidas por Italia en el plano estratégico habían permanecido sobre el papel -caso, por ejemplo, del acuerdo de noviembre de 1936 - sin que se hubiesen realizado verdaderos esfuerzos por desarrollarlas en una línea más clarificadora y, por ende también más comprometedora. En segundo lugar que el equilibrio de fuerzas en el seno de la alianza contrarrevolucionaria que capitaneaba, y balanceaba, Franco, no excluía, en el plano de la política interior, una posible reorientación del régimen en un sentido neo-autoritario más próximo al punto de vista de los sectores conservadores y reaccionarios tradicionales; ni parecidas basculaciones en dirección filobritánica $y$, menos, filofrancesa, en el de la política exterior.

No creo sin embargo que se pueda o se deba ir demasiado lejos en esta dirección. Y ello porque la premisa básica que subyacía en este conjunto de problemas, al menos desde una óptica mussoliniana, era que Italia estaria desempeñando entre tanto el papel de potencia de primer orden. $Y$ era esta precisamente la premisa que iba a fallar provocando el derrumbe de todo el edificio.

Porque, en efecto, la gran paradoja de la intervención italiana en la guerra civil española estriba en el hecho de los éxitos de Mussolini en España contenian también los elementos del fracaso general de la política exterior fascista. Como hemos visto a lo largo de la exposición, Italia hubo de ver progresivamente aplazado en función de los acontecimientos españoles su deseado settlement con Inglaterra, y cuando lo consiguió en los acuerdos de Pascua de 1938 lo hizo en unas condiciones en las que habia perdido la mayor parte de su operatividad política. Como decíamos anteriormente, el deseado acuerdo general con Inglaterra debia suponer en el cuadro general de la política exterior fascista un periodo-rellano de indefinida duración a la espera del inevitable enfrentamiento final. Los 
obstáculos que la guerra de España interponia sucesivamente a la aproximación italo-británica forzaban a Mussolini a precipitar los pasos en dirección a Alemania (con la intención de presionar sobre Inglaterra para que ésta se aviniese a la negociación con Italia). Pero esos pasos en dirección a Alemania traían como consecuencia, mientras el freno español siguiese operante, una ulterior limitación de su margen de maniobra. Es decir, Mussolini se aproximaba a Alemania de una forma mucho más rápida y, sobre todo, más subordinada de cuanto inicialmente habría deseado. Si a esto unimos que, paralelamente, la existencia del conflicto español incrementaba las posibilidades de movimiento de la Alemania nazi, nos encontraremos con un cuadro ciertamente poco favorable para Italia: su actuación en España habría contribuido a acelerar los procesos que condujeron a la II Guerra Mundial, hasta el punto de que ésta estalló al menos dos años antes de cuando Italia hubiese deseado. Cuando Mussolini se incorporó a la guerra mundial desatando su guerra paralela, lo hizo en unas condiciones tales que pronto perdió toda capacidad de iniciativa. Afrontada la guerra en estas condiciones ni siquiera pudo utilizar la baza por la que tan alto precio había pagado: el aliado español.

En septiembre de 1939 estallaba la II Guerra Mundial con la notable inhibición de las dos potencias que mayor protagonismo activo habían tenido en la guerra civil española: Italia y la URSS. Las razones de ello son complejas pero sus consecuencias historiográficas claras: la guerra de España se perderia en la mayoría de las reconstrucciones históricas como un factor fundamental y decisivo en el camino que condujo a la guerra general. Quizá haya otra razón para explicar esta laguna historiográfica: la dificultad para establecer el modo en el que el conflicto español se entrecruzó con los otros elementos clave en la evolución de las relaciones internacionales. Pero las dificultades no excusan la tarea y la temporánea ausencia de Italia y la URSS fue pronto corregida.

No es este el momento de intentar dicho análisis, pero si quisiera enunciar algunas breves consideraciones que, entiendo, merecen la atención de la historiografía: pérdida de la libertad de movimientos por parte de Italia y cimentación sobre bases político-ideológicas de la alianza italogermana; contribución a la creación de las condiciones que facilitaron la aceleración del programa expansionista alemán; papel nada despreciable de la experiencia española en el abandono por parte soviética de las esperanzas de colaboración con las democracias occidentales y su consiguiente vuelta hacia Berlín ${ }^{41}$; evolución de las contradicciones internas del Foreign Office y los medios conservadores británicos hasta el punto

\footnotetext{
${ }^{41}$ Haslam, J., The Soviet Union..., op. cit, pág. 231.
} 
de que buena parte del equipo político que condujo el decisivo esfuerzo de guerra maduró muchas de sus concepciones en relación al problema español (Churchill, Eden..)

Uno de los más prestigiosos historiadores del siglo $x x$, el italiano Mario Toscano escribió hace casi 30 años que la guerra de España habia supuesto «la introducción definitiva del factor ideológico en la evolución de la politica exterior prebélica». Aceptando la profunda verdad de dicha afirmación yo añadiría algo más: la guerra de España fue absolutamente fundamental para la sustitución de una percepción dominante en amplios sectores de la opinión pública europea y mundial -la prevención anticomunista, el miedo a la revolución- por otra: la del fascismo como peligro mayor para la democracia y la paz. Y creo que en esto tuvo bastante «mérito» el propio Mussolini y su intervención en España. Más arriba señalaba que el gran fallo de la política fascista en España estuvo en su incapacidad para controlar la complejidad de los cambios internacionales que en su contexto se produjeron. Pues bien, el otro gran fallo radicó precisamente en esto: en su incapacidad para calibrar el alcance ideológico en el reino de las libres instituciones y de la libre opinión pública de su aventura ideológica en España. 